\title{
Association of serum uric acid with high-sensitivity C-reactive protein in postmenopausal women
}

\author{
A. Raeisi, A. Ostovar, K. Vahdat, P. Rezaei, H. Darabi, D. Moshtaghi \& I. \\ Nabipour
}

To cite this article: A. Raeisi, A. Ostovar, K. Vahdat, P. Rezaei, H. Darabi, D. Moshtaghi \& I. Nabipour (2017) Association of serum uric acid with high-sensitivity C-reactive protein in postmenopausal women, Climacteric, 20:1, 44-48, DOI: 10.1080/13697137.2016.1247261

To link to this article: http://dx.doi.org/10.1080/13697137.2016.1247261

\section{曲 Published online: 19 Oct 2016.}

Submit your article to this journal $\sqsubset$

山 Article views: 17

Q View related articles $\square$

View Crossmark data ¿ 


\title{
Association of serum uric acid with high-sensitivity C-reactive protein in postmenopausal women
}

\author{
A. Raeisi ${ }^{\text {a }}$, A. Ostovar ${ }^{\mathrm{a}}$, K. Vahdat ${ }^{\mathrm{a}}$, P. Rezaei ${ }^{\mathrm{a}}$, H. Darabi ${ }^{\mathrm{a}}$, D. Moshtaghi ${ }^{\mathrm{a}}$ and I. Nabipour ${ }^{\mathrm{b}}$

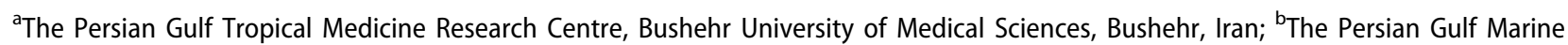 \\ Biotechnology Research Centre, Bushehr University of Medical Sciences, Bushehr, Iran
}

\begin{abstract}
Objectives: To explore the independent correlation between serum uric acid and low-grade inflammation (measured by high-sensitivity C-reactive protein, hs-CRP) in postmenopausal women.

Methods: A total of 378 healthy Iranian postmenopausal women were randomly selected in a population-based study. Circulating hs-CRP levels were measured by highly specific enzyme-linked immunosorbent assay method and an enzymatic calorimetric method was used to measure serum levels of uric acid. Pearson correlation coefficient, multiple linear regression and logistic regression models were used to analyze the association between uric acid and hs-CRP levels.

Results: A statistically significant correlation was seen between serum levels of uric acid and log-transformed circulating hs-CRP $(r=0.25, p<0.001)$. After adjustment for age and cardiovascular risk factors (according to NCEP ATP III criteria), circulating hs-CRP levels were significantly associated with serum uric acid levels $(\beta=0.20, p<0.001)$. After adjustment for age and cardiovascular risk factors, hs-CRP levels $\geq 3 \mathrm{mg} / \mathrm{l}$ were significantly associated with higher uric acid levels (odds ratio $=1.52,95 \%$ confidence interval 1.18-1.96).

Conclusion: Higher serum uric acid levels were positively and independently associated with circulating hs-CRP in healthy postmenopausal women.
\end{abstract}

ARTICLE HISTORY

Received 13 May 2016

Revised 9 September 2016

Accepted 8 October 2016

Published online 19 October 2016

\section{KEYWORDS}

Uric acid; C-reactive protein; postmenopause;

inflammation

\section{Introduction}

Numerous studies have clearly established that C-reactive protein (CRP) as a marker of low-grade inflammation can predict future coronary artery disease in apparently healthy persons $^{1,2}$. In a large and comprehensive meta-analysis, the Emerging Risk Factor Collaboration reported that CRP concentration had continuous associations with subsequent risk of coronary heart disease, ischemic stroke, and deaths from vascular and non-vascular diseases ${ }^{3}$. CRP is not only a biomarker for prediction of cardiovascular diseases but also has direct effects in atherosclerotic mechanisms because it is present in atherosclerotic plaques ${ }^{4}$.

Recent experimental, clinical, and epidemiological studies have shown that hyperuricemia may cause endothelial dysfunction and pathologic vascular remodeling, and hence play a role in the pathogenesis of hypertension and progressive renal failure, cardiovascular diseases, stroke, chronic heart failure, type 2 diabetes mellitus, insulin resistance and the metabolic syndrome ${ }^{5-11}$.

Uric acid may have direct proinflammatory effects on vascular smooth muscle cells (VSMCs) because soluble uric acid induces inflammatory pathways in rat VSMCs in vitro ${ }^{12}$. Therefore, it has been suggested that uric acid may play a role in vascular changes associated with cardiovascular diseases $^{12}$. In mice studies, it has been shown that hyperuricemia may trigger production of proinflammatory cytokines such as tumor necrosis factor- $\alpha(\text { TNF- } \alpha)^{13}$. Soluble uric acid induces CRP mRNA expression in human vascular endothelial and smooth muscle cells with a concomitant increase in CRP release into cell culture media ${ }^{5}$.

Although remarkable common features in vascular changes have been shown for uric acid and CRP in vitro studies $^{5,12,13}$, there are few population-based studies in medical literature to reveal the association between uric acid levels and inflammatory biomarkers ${ }^{14-17}$. A statistically significant positive crude correlation between CRP and uric acid was found in a German population-based study ${ }^{14}$. A positive and significant association between uric acid levels and inflammatory biomarkers including CRP, TNF- $\alpha$ and IL- 6 was reported among older persons ${ }^{15}$.

There are no clear data on whether the relationship between uric acid and low-grade inflammation is significant when other vascular risk factors are considered ${ }^{18}$. However, the significant association between uric acid and CRP persisted after controlling for potential confounders such as body mass index ${ }^{16}$ and metabolic syndrome ${ }^{17}$. The present population-based study sought to explore the independent correlation between serum uric acid and low-grade inflammation (measured by hs-CRP) in postmenopausal women. 


\section{Methods}

\section{Community sampling and physical examinations}

The study design has been described elsewhere ${ }^{19}$. Briefly, participants in the present study were an age-stratified random sample of 378 postmenopausal women who participated in the extension part of the Iranian Multicentral Osteoporosis Study (IMOS). The subjects were randomly selected from 13 clusters in the port city of Bushehr (the capital of Bushehr Province, southern part of Iran). All of the women, who were community-dwelling and ambulatory, were asked to fast and to come to the survey center between 07.30 and 09.30. Blood pressure was assessed twice at the right arm after a 15 -min rest in the sitting position, using a standard mercury sphygmomanometer. Height was measured using a stadiometer and weight was measured after removing heavy outer garments and shoes, and body mass index (BMI) was calculated as weight ( $\mathrm{kg}$ ) divided by squared height in meters.

\section{Laboratory measurements}

Fasting blood samples were taken and promptly centrifuged and separated, and analyses were carried out at the Persian Gulf Health Research Center on the day of blood collection using a Selectra 2 autoanalyzer (Vital Scientific, Spankeren, Netherlands). An enzymatic, calorimetric method was used to measure serum levels of uric acid using Toos commercial kit (Pars Azmun Inc., Tehran, Iran). Glucose was assayed by the enzymatic (glucose oxidase) colorimetric method using a commercial kit (Pars Azmun Inc., Tehran, Iran). Serum total cholesterol and high density lipoprotein (HDL) cholesterol were measured using a cholesterol oxidase phenol aminoantipyrine; triglycerides were measured using a glycerol-3 phosphate oxidase phenol aminoantipyrine enzymatic method. Serum low density lipoprotein (LDL) cholesterol was calculated using the Friedewald formula; LDL cholesterol was not calculated when the triglyceride concentration was $>400 \mathrm{mg} / \mathrm{dl}$.

CRP was measured by using CRP HS enzyme-linked immunosorbent assay (ELISA) (DRG International), a hs-CRP assay. A concentration of $0.1 \mathrm{mg} / \mathrm{l}$ for CRP was estimated to be the lowest detectable concentration in the CRP HS ELISA assay. According to inter-assay coefficient of variation $<20 \%$, the functional sensitivity of CRP measurement was determined to be $0.1 \mathrm{mg} / \mathrm{l}$.

\section{Definitions}

Using the American Diabetes Association criteria, either a fasting plasma glucose level $\geq 126 \mathrm{mg} / \mathrm{dl}$ or use of anti-diabetic measures was defined as diabetes ${ }^{20}$. A subject was considered hypertensive if her blood pressure was at least 140/ $90 \mathrm{mmHg}$. The cut-off points of serum total cholesterol, HDL cholesterol and LDL cholesterol, and serum triglyceride distributions used to assign subjects to different levels of risk were derived from the National Cholesterol Education
Program (NCEP) guidelines in the United States (Adult Treatment Panel, ATP III) ${ }^{21}$.

\section{Statistical analysis}

The distribution of variables was studied using probability plots and the Shapiro-Wilk test. It was found that log transformation of hs-CRP levels was a better fit to a Gaussian distribution. The geometric mean for those biochemical variables was defined as the arithmetic mean of the log-transformed data \pm standard deviation, raised to the power of 10 .

A two-tailed independent group $t$-test was used to compare the mean values across groups. Pearson's correlation coefficient was used to study the relationships between logtransformed hs-CRP and uric acid values. A partial correlation analysis was performed to assess the association between uric acid and hs-CRP levels, adjusted for age and BMI.

Multiple linear regression models were used to assess the association between uric acid levels (independent variables) and hs-CRP levels (dependent variable); in the full model, cardiovascular risk factors (according to NCEP, ATP III criteria) were considered as covariates.

The binary multiple logistic regression model was used to ascertain the associations between circulating hs-CRP $(\geq 3 \mathrm{mg} / \mathrm{l}$ versus $<3 \mathrm{mg} / \mathrm{l})$ and uric acid levels; cardiovascular risk factors (according to NCEP ATP III criteria) were considered covariates. According to the clinical guidelines issued by the American Heart Association and the Centers for Disease Control and Prevention, levels of hs-CRP of more than $3 \mathrm{mg} / \mathrm{l}$ was considered as higher cardiovascular risk ${ }^{22}$.

A $p$ value lower than 0.05 was accepted as significant. All statistical analyses were performed using PASW Statistics GradPack 18 (SPSS Inc., Chicago, IL, USA).

\section{Results}

The mean age ( \pm standard deviation) of the women was $58.78 \pm 7.82$ years. The participants (378 postmenopausal women) were stratified into low (lower than or equal to the median) and high (higher than the median) serum uric acid groups. Table 1 shows the baseline characteristics of the studied postmenopausal women, stratified by uric acid groups. Women with high uric acid levels had higher BMI and hs-CRP levels than women with low uric acid levels.

Uric acid levels were significantly correlated with circulating hs-CRP in the studied population $(r=0.25, p<0.001)$. Figure 1 illustrates the scatterplot and linear prediction fit line of log-transformed hs-CRP and uric acid levels. This correlation persisted after adjustment for age $(r=0.27$, $p<0.001)$ and BMI $(r=0.20, p<0.001)$.

By dichotomization of hs-CRP levels to $\geq 3 \mathrm{mg} / \mathrm{l}$ and $<3 \mathrm{mg} / \mathrm{l}$, we found that postmenopausal women with hs-CRP levels $\geq 3 \mathrm{mg} / \mathrm{l}$ had significantly higher circulating uric acid levels than those with hs-CRP levels $<3 \mathrm{mg} / \mathrm{l}$ $(5.08 \pm 1.23 \mathrm{mg} / \mathrm{dl}$ vs. $4.50 \pm 0.96 \mathrm{mg} / \mathrm{dl}, p<0.0001)$.

In multiple linear regression analysis, after adjustment for age, type 2 diabetes mellitus, hypertension, obesity and dyslipidemia, circulating hs-CRP levels were significantly 
Table 1. The general characteristics, including blood pressure, anthropometric measurements, and the biochemical parameters of postmenopausal women stratified by serum uric acid levels below/equal or above median. Data are given as mean \pm standard deviation.

\begin{tabular}{lccr}
\hline & $\begin{array}{c}\text { Uric acid below or } \\
\text { equal to median }\end{array}$ & $\begin{array}{c}\text { Uric acid } \\
\text { above median }\end{array}$ & p Value \\
\hline Age (years) & $58.04 \pm 7.33$ & $59.59 \pm 8.58$ & 0.081 \\
Body mass index $\left(\mathrm{kg} / \mathrm{m}^{2}\right)$ & $27.49 \pm 4.67$ & $29.34 \pm 4.74$ & $<0.001$ \\
Systolic blood pressure $(\mathrm{mmHg})$ & $125.26 \pm 19.61$ & $127.27 \pm 19.97$ & 0.361 \\
Diastolic blood pressure $(\mathrm{mmHg})$ & $78.51 \pm 10.71$ & $81.15 \pm 25.91$ & 0.232 \\
Total cholesterol (mg/dl) & $230.41 \pm 45.80$ & $236.64 \pm 47.83$ & 0.245 \\
High density lipoprotein & $41.61 \pm 10.36$ & $40.42 \pm 11.09$ & 0.317 \\
$\quad$ & & & \\
$\quad$ cholesterol (mg/dl) & $153.29 \pm 41.61$ & $157.71 \pm 42.68$ & 0.345 \\
$\quad$ & & \\
$\quad$ cholesterol (mg/dl) & $177.58 \pm 93.83$ & $191.75 \pm 100.85$ & 0.191 \\
Triglyceride (mg/dl) & $116.85 \pm 54.64$ & $180.86 \pm 38.34$ & 0.128 \\
Fasting blood glucose (mg/dl) & $1.36 \pm 2.75^{\mathrm{a}}$ & $2.60 \pm 2.60^{\mathrm{a}}$ & $<0.001$ \\
hs-CRP (mg/l) & & & \\
\hline a Geometric mean \pm standard deviation & & &
\end{tabular}

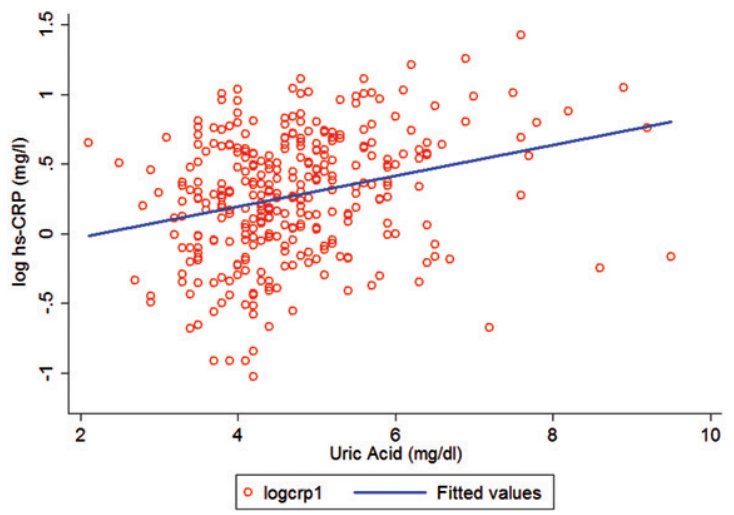

Figure 1. Scatterplot of log hs-CRP and uric acid and fitted values in postmenopausal women.

Table 2. Multiple linear regression analysis for the association between circulating hs-CRP (dependent variable) and serum uric acid levels (independent variable) in different models. Full model included serum uric acid, type 2 diabetes mellitus, hypertension, obesity and dyslipidemia.

\begin{tabular}{lcc}
\hline & $\beta$ & $p$ Value \\
\hline Unadjusted & 0.25 & $<0.001$ \\
Age-adjusted & 0.27 & $<0.001$ \\
Age-, body mass index-adjusted & 0.27 & $<0.001$ \\
Full model & 0.20 & $<0.001$ \\
\hline
\end{tabular}

correlated with serum uric acid levels $(\beta=0.20, p<0.001)$ (Table 2).

After adjustment for potential confounders including classical cardiovascular risk factors, hs-CRP levels $\geq 3 \mathrm{mg} / \mathrm{l}$ were significantly associated with higher uric acid levels in the multivariable logistic regression model (odds ratio $=1.52$, $95 \%$ confidence interval 1.18-1.96, $p=0.001$ ).

\section{Discussion}

In a population-based study, we showed a strong correlation between serum uric acid and hs-CRP in Iranian postmenopausal women, independent of cardiovascular risk factors.
Similar findings were reported from a National Health and Nutrition Survey in Germany ${ }^{14}$, from a representative Italian cohort of persons aged 65-95 years ${ }^{15}$, from a populationbased study in Switzerland ${ }^{16}$, and in health examinations among employed subjects in Brazil ${ }^{17}$. Ruggiero and colleagues ${ }^{15}$ found a progressive increase in frequency of subjects with abnormal levels of IL-6 and CRP in communitydwelling older persons. In contrast, circulating uric acid was not associated with inflammatory markers in elderly men in Taiwan $^{23}$.

Although the findings of the current study and other cross-sectional studies could not illustrate whether uric acid is a causal risk factor for hs-CRP and vascular disease, Ruggiero and colleagues ${ }^{24}$ found that baseline uric acid levels and changes in circulating uric acid predicted a 3-year change in CRP in a cohort of Italian men and women aged 21-98 years. In in vitro studies, it has been shown that uric acid could induce expression of CRP in smooth muscle cells and vascular endothelial cells ${ }^{5}$. Uric acid-induced CRP expression and vascular remodeling suggest a role for uric acid in hypertension and cardiovascular diseases ${ }^{5}$. In male and female subjects, CRP and uric acid were consistently associated with an increase in arterial stiffness ${ }^{25}$.

We found that the association between uric acid and hsCRP still remained significant after adjustment for BMI. This finding is consistent with data of Keenan and colleagues ${ }^{17}$. These findings suggest that uric acid might be independently related to hs-CRP and this association is beyond obesity. However, in the population-based Colaus study, the association between uric acid and CRP was attenuated upon further adjustment for $\mathrm{BMI}^{16}$.

In prospective studies, it has been shown that hs-CRP levels $\geq 3 \mathrm{mg} / \mathrm{l}$ are associated with increased cardiovascular risk $^{26}$. Ridker and colleagues ${ }^{27}$ reported CRP as a stronger predictor of cardiovascular events than LDL cholesterol level in apparently healthy American women who were followed for a mean of 8 years. In the current study, we found that postmenopausal women with hs-CRP levels $\geq 3 \mathrm{mg} / \mathrm{l}$ had significantly higher uric acid levels, and hs-CRP levels $\geq 3 \mathrm{mg} / \mathrm{l}$ were positively and significantly associated with circulating uric acid, independent of established cardiovascular risks. These findings were consistent with the study results of Keenan and colleagues ${ }^{17}$ who found the highest versus lowest uric acid quartile was associated with hs-CRP levels $\geq 3 \mathrm{mg} / \mathrm{l}$ after adjusting for traditional cardiovascular risk factors. Therefore, one could speculate that uric acid and hsCRP levels might be equivalent to each other. In fact, in the Bezafibrate Infarction Prevention (BIP) trial, uric acid and CRP measurements provided similar prognostic information for risk stratification of patients with coronary artery disease ${ }^{28}$. In addition, combined assessment of uric acid and CRP levels provides incremental information for risk assessment of cardiac events in patients with coronary artery disease ${ }^{28}$.

The data from current experimental and population-based studies are in line with the hypothesis that uric acid stimulates vascular smooth muscles to produce proinflammatory markers including CRP that have a direct role in the inflammatory cascade associated with atherosclerosis. Hence, it is not surprising that the available evidence is going to 
establish a causal link between hyperuricemia and cardiovascular outcomes ${ }^{29,30}$. However, clinical trials are needed to assess the relevance of apparently sustained falls in hs-CRP after the use of uric acid-lowering drugs as well as apparent decreases in cardiovascular outcomes and mortality. The Serum Urate Reduction to Prevent Hypertension (SURPHER) study, a double-blinded, cross-over trial on adults 18-40 years old, has now been launched to determine potential for urate-lowering therapies to decrease blood pressure and CRP levels $^{31}$.

The strengths of this study are its population-based design, existing information about cardiometabolic risk conditions of the participants for their adjustment as confounders in regression models, and particularly addressing postmenopausal women for the first time who have higher serum uric acid levels ${ }^{32}$. However, we acknowledge several study limitations. A causal relationship between uric acid and hs-CRP could not be clarified in our cross-sectional study. We assessed uric acid and hs-CRP with single measurements, and therefore changes in circulating uric acid and this acutephase reactant over time could not be reflected in our study. Although this study is the first population-based study that has investigated a link between circulating uric acid and hsCRP in menopause, its findings should be confirmed in further human studies with larger samples. Finally, to elucidate the complex system that regulates uric acid and low-grade inflammation, the concurrent measurement of additional inflammatory markers and cytokines, including TNF- $\alpha$ and IL-6, merits consideration.

In conclusion, our findings comply with those of previous population-based studies showing an independent positive association between uric acid levels and low-grade inflammation as measured by hs-CRP. Clinical trials are needed to assess the relevance of apparently sustained falls in hs-CRP after the use of uric acid-lowering drugs as well as apparent decreases in cardiovascular outcomes and mortality.

Conflict of interest The authors report no conflict of interest. The authors alone are responsible for the content and writing of this paper.

\section{Source of funding Nil.}

\section{References}

1. Danesh J, Wheeler JG, Hirschfield GM, et al. C-reactive protein and other circulating markers of inflammation in the prediction of coronary heart disease. N Engl J Med 2004;350:1387-97

2. Danesh J, Whincup $P$, Walker $M$, et al. Low grade inflammation and coronary heart disease: prospective study and updated metaanalyses. BMJ 2000;321:199-204

3. Kaptoge $\mathrm{S}$, Di Angelantonio $\mathrm{E}$, Lowe $\mathrm{G}$, et al. C-reactive protein concentration and risk of coronary heart disease, stroke, and mortality: an individual participant meta-analysis. Lancet 2010;375:132-40

4. Zhang YX, Cliff WJ, Schoefl Gl, Higgins G. Coronary C-reactive protein distribution: its relation to development of atherosclerosis. Atherosclerosis 1999;145:375-9

5. Kang DH, Park SK, Lee IK, Johnson RJ. Uric acid-induced C-reactive protein expression: implication on cell proliferation and nitric oxide production of human vascular cells. J Am Soc Nephrol 2005;16:3553-62
6. Edwards NL. The role of hyperuricemia and gout in kidney and cardiovascular disease. Cleve Clin J Med 2008;75(Suppl 5):S13-S16

7. Puig JG, Martinez MA. Hyperuricemia, gout and the metabolic syndrome. Curr Opin Rheumatol 2008;20:187-91

8. Nakagawa $T$, Cirillo $P$, Sato $W$, et al. The conundrum of hyperuricemia, metabolic syndrome, and renal disease. Intern Emerg Med 2008;3:313-18

9. Johnson RJ, Kang DH, Feig $D$, et al. Is there a pathogenetic role for uric acid in hypertension and cardiovascular and renal disease? Hypertension 2003;41:1183-90

10. Kim SY, Guevara JP, Kim KM, Choi HK, Heitjan DF, Albert DA Hyperuricemia and risk of stroke: a systematic review and metaanalysis. Arthritis Rheum 2009;61:885-92

11. Dehghan A, van Hoek M, Sijbrands EJ, Hofman A, Witteman JC. High serum uric acid as a novel risk factor for type 2 diabetes. Diabetes Care 2008;31:361-2

12. Kanellis J, Watanabe $\mathrm{S}$, $\mathrm{Li} \mathrm{JH}$, et al. Uric acid stimulates monocyte chemoattractant protein-1 production in vascular smooth muscle cells via mitogen-activated protein kinase and cyclooxygenase-2. Hypertension 2003;41:1287-93

13. Netea MG, Kullberg BJ, Blok WL, Netea RT, van der Meer JW. The role of hyperuricemia in the increased cytokine production after lipopolysaccharide challenge in neutropenic mice. Blood 1997;89:577-82

14. Frohlich $M$, Imhof A, Berg G, et al. Association between C-reactive protein and features of the metabolic syndrome: a populationbased study. Diabetes Care 2000;23:1835-9

15. Ruggiero $C$, Cherubini $A$, Ble $A$, et al. Uric acid and inflammatory markers. Eur Heart J 2006;27:1174-81

16. Lyngdoh T, Marques-Vidal P, Paccaud F, et al. Elevated serum uric acid is associated with high circulating inflammatory cytokines in the population-based Colaus study. PLoS One 2011;6(5):e19901

17. Keenan T, Blaha MJ, Nasir K, et al. Relation of uric acid to serum levels of high-sensitivity C-reactive protein, triglycerides, and highdensity lipoprotein cholesterol and to hepatic steatosis. Am J Cardiol 2012;110:1787-92

18. Tziomalos K, Athyros VG, Karagiannis A, et al. Pitfalls in the evaluation of uric acid as a risk factor for vascular disease. Open Clin Chem J 2010;3:44-5

19. Nabipour I, Larijani B, Beigi S, et al. Relationship among insulin like growth factor I concentrations, bone mineral density, and biochemical markers of bone turnover in postmenopausal women: a population-based study. Menopause 2008;15:934-9

20. Report of the Expert Committee on the Diagnosis and Classification of Diabetes Mellitus. Diabetes Care 1997;20:1183-97

21. Executive Summary of The Third Report of The National Cholesterol Education Program (NCEP) Expert Panel on Detection, Evaluation, And Treatment of High Blood Cholesterol In Adults (Adult Treatment Panel III). JAMA 2001;285:2486-97

22. Pearson TA, Mensah GA, Alexander RW, et al. Markers of inflammation and cardiovascular disease application to clinical and public health practice: a statement for healthcare professionals from the Centers for Disease Control and Prevention and the American Heart Association. Circulation 2003;107:499-511

23. Chang $\mathrm{CH}$, Chen YM, Chuang YW, et al. Relationship between hyperuricemia (HUC) and metabolic syndrome (MS) in institutionalized elderly men. Arch Gerontol Geriatr 2009;49(Suppl2): S46-9

24. Ruggiero C, Cherubini A, Miller E 3rd, et al. Usefulness of uric acid to predict changes in C-reactive protein and interleukin-6 in 3-year period in Italians aged 21 to 98 years. Am J Cardiol 2007;100: $115-21$

25. Saijo $\mathrm{Y}$, Utsugi M, Yoshioka E, et al. Relationships of C-reactive protein, uric acid, and glomerular filtration rate to arterial stiffness in Japanese subjects. J Hum Hypertens 2005;19:907-13

26. Buckley DI, Fu R, Freeman M, Rogers K, Helfand M. C-reactive protein as a risk factor for coronary heart disease: a systematic review 
and meta-analyses for the U.S. Preventive Services Task Force. Ann Intern Med 2009;151:483-95

27. Ridker PM, Rifai N, Rose L, Buring JE, Cook NR. Comparison of Creactive protein and low-density lipoprotein cholesterol levels in the prediction of first cardiovascular events. $N$ Engl J Med 2002;347:1557-65

28. Brodov Y, Behar S, Goldenberg I, Boyko V, Chouraqui P. Usefulness of combining serum uric acid and C-reactive protein for risk stratification of patients with coronary artery disease (Bezafibrate Infarction Prevention [BIP] study). Am J Cardiol 2009;104:194-8

29. Krishnan E, Sokolove J. Uric acid in heart disease: a new C-reactive protein? Curr Opin Rheumatol 2011;23:174-7
30. Rothenbacher D, Kleiner A, Koenig W, Primatesta P, Breitling $L P$, Brenner $H$. Relationship between inflammatory cytokines and uric acid levels with adverse cardiovascular outcomes in patients with stable coronary heart disease. PLoS One 2012;7(9): e45907

31. Saddekni MB, Saag KG, Dudenbostel T, et al. The effects of urate lowering therapy on inflammation, endothelial function, and blood pressure (SURPHER) study design and rationale. Contemp Clin Trials 2016;50238-44

32. Hak AE, Choi HK. Menopause, postmenopausal hormone use and serum uric acid levels in US women - the Third National Health and Nutrition Examination Survey. Arthritis Res Ther 2008;10:R116 